applicable. ${ }^{4}$ The international stroke trial plans to recruit about 20000 patients from 500-600 hospitals in 40 countries worldwide and should be reporting its results in 1996.

The pharmaceutical industry is investing large amounts of money in developing and testing several new compounds, which are now entering clinical trials in patients with acute stroke. These compounds have a common aim: to protect neurones from the damaging effects of ischaemia by inhibiting excitatory amino acid neurotransmitters such as glutamate, by reducing the influx of calcium, and by reducing concentrations of free radicals. Other neuroprotective agents such as magnesium also seem promising

In future, if they are proved to be safe and effective, some of the simpler treatments may be offered routinely to most patients with acute stroke. Treatments with a higher risk of complications may be offered only to a selected few. Whatever the results of the current trials of medical treatment, one thing is certain: hospitals must act now to develop organised systems of care for patients with acute stroke.

PETER SANDERCOCK

Department of Clinical Neurosciences, Reader in clinical neurology

Western General Hospital,

Edinburgh EH4 2XU

1 Langhorne $P$, Williams B, Gilchrist W, Howie $K$. Do stroke units save lives? Lancet 1993;342:395-8. 2 Sandercock P, Willems H. Medical treatment of acute ischaemic stroke. Lancet 1992;339:537-9.

3 Wardlaw J, Warlow CP. Thrombolysis in acute ischaemic stroke: does it work? Stroke 1992;23: 1826-39.

4 Sandercock PAG, van den Belt AGM, Lindley RI, Slattery J. Antithrombotic therapy in acute ischaemic stroke: an overview of the completed randomised trials. $f$ Neurol Neurosurg Psychiatry 1993;56:17-25.

\title{
Repetitive strain injury
}

\section{Does not exist as a separate medical condition}

Judge Prosser's recent decision in a British court that repetitive strain injury does not exist as a separate medical condition is supported by the overwhelming bulk of carefully conducted studies. Arm pain in the workplace (or any other place) has been around for a long time and will continue to be seen. The real issue is whether it is causally related to particular tasks and, specifically, whether there is any evidence that repetitive movement actually "injures" the body.

Those of us who have watched the debate over repetitive strain injury have seen the same issues raised first in Australia, then in America, and now in Britain. Auberon Waugh's prophesy, made seven years ago, that this condition would spread to Britain ${ }^{1}$ unfortunately turns out to be right. This has occurred despite an enormous effort in Australia to get rid of the term repetitive strain injury, with groups such as the Royal Australasian College of Physicians canvassing to reduce the emphasis on "injury" and describe the condition for what it really is-a pain syndrome. ${ }^{2}$

In Australia the epidemic surfaced in the early 1980s and peaked around 1986. During those years the idea of "injury" was emphasised, spawning a whole range of new consultancies in an attempt to cope with the problem. Doctors (both physicians and surgeons), allied health professionals, and, in particular, designers of ergonomic furniture all cashed in on the condition. Gone are the days when you can equip an office with a simple chair and a desk. This equipment must be ergonomically designed. There is no evidence that using ergonomically designed furniture has altered the incidence of arm or any other pain in the workplace, yet these changes have been introduced at enormous cost and with little evaluation. Of greater importance are the psychosocial aspects of the workplace-the need to provide appropriate work breaks and to keep stress to a minimum.

Very few properly controlled epidemiological studies have been carried out on arm pain in the workplace, but those that have would suggest very little, if any, relation with the type of computer equipment used or the type of work performed. Indeed, a study of arm pain in the workplace at Telecom Australia showed an inverse relation between the number of keyboard strokes performed and the incidence of the condition. ${ }^{3}$

None of this is to deny that pain occurs in the workplace, but the association of that pain with any particular type of work has not been clearly proved. Hadler has carefully explained the difficulties inherent in assessing some of these studies when up to $9 \%$ of a population have suffered pain or discomfort in the arm in the preceding month. ${ }^{4}$ As Ferguson stated in an editorial in the Medical. Fournal of Australia, "With hindsight, the gigantic and costly epidemic called repetitive strain injury (RSI) can be seen as a complex psychosocial phenomenon with elements of mass hysteria that was superimposed on a base of widespread discomfort, fatigue, and morbidity. The epidemic, to which the medical and legal professions, management, unions, governments, and media have all contributed, is now waning but endemic work related musculoskeletal syndromes remain."5

Some argue that simply discussing the terminology is facile, yet reducing the emphasis on the injury component of repetitive strain injury was important in helping Australians cope with the problem. Repetitive strain injury has become an emotive term and is patently incorrect: the term implies a repetitive injury (as opposed simply to repetitive motion) and damage to tissues, which has never been shown in this condition. Alternative terms, such as occupational overuse syndrome, also promote social iatrogenesis because, in the context of workers' compensation laws, any diagnosis that includes the term "occupational" is likely to encourage a worker to claim for disability compensation. ${ }^{6}$

Although Judge Prosser's judgement will undoubtedly be criticised, he will have performed a good service if his decision discourages people from seeking damages in the courts. Instead workers, employers, and their advisers should pay attention to workplace factors, active rehabilitation, preventing the use of splinting (which promotes only reflex sympathetic dystrophy), denying compensation, and removing the emphasis on injury. As a result of paying attention to these factors the incidence of arm pain in the workplace in Australia has fallen dramatically.

PETER BROOKS

St Vincent's Hospital, Professor of medicine

Darlinghurst,

NSW 2010,

Australia

1 Waugh A. Introducing kangaroo's paw-a wonderful new disease from Australia. Spectator 1986;15 Nov:8.

2 RACP wants name "RSI" changed. Fellowship Affiars 1986;Sept.

3 Hocking B. Epidemiological aspects of "repetition strain injury" in Telecom Australia. Med $\mathcal{F}$ Aust 1987;142:218-22.

4 Hadler NM. The roles of work and of working in disorders of the upper extremity. Baillieres Clin Rheumatol 1989;3:121-41.

5 Ferguson DA. "RSI"-putting the epidemic to rest. Med f Aust 1987;147:213-4

6 Cleland LG. "RSI": a model of social iatrogenesis. Med $¥$ Aust 1987;147:236-9. 